\title{
Synthesis of Novel Pyrazolinecarbothioamide and Evaluation of Its Anti-Cancer Activity
}

\author{
Dongsoo Koh
}

\author{
새로운 피라졸린카르보티오아미드 화합물의 합성과 항암효과 \\ 고 동 수
}

Received: 19 June 2012 / Accepted: 20 July 2012 / Published Online: 30 September 2012

(C) The Korean Society for Applied Biological Chemistry 2012

\begin{abstract}
Novel pyrazolinecarbothioamide (5) was synthesized from chalcone (3) which was prepared from 2'-hydroxy-1'acetonaphthone (1) and 2-methoxy benzaldehyde (2). Treatment of pyrazolinecarbothioamide (5) on HCT116 cancer cell showed upregulation of p21 and downregulation of cyclin D1 protein. Flowcytometer analysis revealed that pyrazolinecarbothioamide (5) controls the expression of cell cycle regulatory proteins, which blocks cell cycle progression of HCT116 cancer cell at the G1 phase.
\end{abstract}

Keywords anti-cancer $\cdot$ cell cycle $\cdot$ chalcone $\cdot$ cyclin D1 pyrazolinecarbothioamide

Chalcones 화합물들은 광범위한 생리활성을 보이는 flavanones, flavones의 전구체가 될 뿐만 아니라, 그 자체로도 다양한 생리 활성을 나타낸다(Bazzaro 등, 2011; $\mathrm{Wu}$ 등, 2011; Hsieh 등, 2012). Chalcones과 hydrazine 간의 반응을 통해 생성되는 pyrazoline계열의 화합물들 또한 항염증(anti-inflammatory) (Joshi 등, 2010), 항균(antibacterial) (Siddiqui 등, 2011), 항암(anticancer) (Bano 등, 2011) 작용 등 광범위한 생리학적 활성을 나타내는 것으로 보고되고 있다. 특별히 pyrazoline에 thiocarbamoyl 기를 포함하는 피라졸린카르보티오아미드(pyrazolinecarbothioamide) 계열의 화합물들이 다양한 생리 활성을 보이는 것으로 최근 보 고되고 있다(Maccioni 등, 2010; Ahsan 등, 2011).

항암과정을 설명하는 다양한 메카니즘 연구 중에서 세포주기 조절은 중요한 연구 영역이다(Gao 등, 2007; Rao 등, 2010).

D. Koh $(\triangle)$

Dept. of Applied Chemistry, Dongduk Women's University, Wolkok-Dong 23-1, Sungbuk-Ku, Seoul 136-714, Republic of Korea

Email: dskoh@dongduk.ac.kr
세포분열 과정에 관여하는 각종 사이클린(Cyclin) 단백질은 세 포주기의 단계를 조절하는데, 이중에서도 사이클린 D1 (Cyclin $\mathrm{D} 1)$ 은 $\mathrm{G} 1$ 단계에서 $\mathrm{S}$ 단계로 진행하는데 있어 중요한 역할을 하는 단백질이다(Cordon-Cardo, 1995). 따라서, 사이클린 D1의 발현량을 감소시키면, 세포주기가 G1 단계에 머무르게 되어 암 세포의 비정상적인 세포분열 및 증식을 막아 암 치료에 적용할 수 있다. 본 연구에서는 새로운 합성물질인 피라졸린카르보티오 아미드(5)를 사용하여 사이클린 $\mathrm{D} 1$ 의 발현량 감소 여부를 확인 하고, 이를 통한 세포주기 진행 억제 효과를 측정하여 이 화합 물이 가지는 항암효과를 보고하고자 한다.

Chalcone 3의 합성. 2-히드록시-1-아세토나프톤 $(1,1.9 \mathrm{~g}, 10$ $\mathrm{mmol})$ 과 2-메톡시벤즈알데히드 $(\mathbf{2}, 1.4 \mathrm{~g}, 10 \mathrm{mmol}$ 를 $20 \mathrm{~mL}$ 에 탄올에 교반 하면서 녹인 후 온도를 약 $3{ }^{\circ} \mathrm{C}$ 낮춘 다음에 $50 \%$ $\mathrm{KOH}$ 용액을 $3 \mathrm{~mL}$ 천천히 첨가하였다. 그 다음 상온에서 20 시 간 교반 후 얼음물에 가하여 냉각시키고, $6 \mathrm{~N}$ 염산 $(\mathrm{HCl})$ 으로 중 화시켜 생성된 고체를 감압 여과하여 칼콘(chalcone) 화합물 $\mathbf{3}$ 을 $87 \%(2.6 \mathrm{~g})$ 의 수율로 얻었다. Chalcone 3 에서 새로 형성된 탄소-탄소 간의 이중결합은 두 탄소에 붙어 있는 수소들(7.72 $\mathrm{ppm}, \mathrm{d} ; 7.91 \mathrm{ppm}, \mathrm{d})$ 사이의 짝지음 상수 $(J=15.4 \mathrm{~Hz})$ 를 통해 trans 이중 결합을 나타내는 것으로 확인되었다. 용융점; $123-$ $124^{\circ} \mathrm{C}$. ${ }^{1} \mathrm{H}-\mathrm{NMR} \quad\left(400 \mathrm{MHz}, \mathrm{CDCl}_{3}\right) \delta 8.50 \quad(\mathrm{~d}, \quad J=8.3 \mathrm{~Hz}$, $1 \mathrm{H}), 7.91(\mathrm{~d}, J=15.4 \mathrm{~Hz}, 1 \mathrm{H}), 7.94(\mathrm{~d}, J=8.9 \mathrm{~Hz}, 1 \mathrm{H}), 7.78$ (d, $J=7.9 \mathrm{~Hz}, 1 \mathrm{H}), 7.72$ (d, $J=15.4 \mathrm{~Hz}, 1 \mathrm{H}), 7.64$ (ddd, $J=8.2,6.9,1.3 \mathrm{~Hz}, 1 \mathrm{H}), 7.51$ (ddd, $J=8.2,6.9,1.2 \mathrm{~Hz}, 1 \mathrm{H}$ ), $7.41-7.34(\mathrm{~m}, 1 \mathrm{H}), 7.34-7.25(\mathrm{~m}, 2 \mathrm{H}), 7.20(\mathrm{~d}, J=1.7 \mathrm{~Hz}$, $1 \mathrm{H}), \quad 7.04-6.97 \quad(\mathrm{~m}, \quad 1 \mathrm{H}), \quad 3.87(\mathrm{~d}, \quad J=9.9 \mathrm{~Hz}, \quad 3 \mathrm{H}){ }^{13} \mathrm{C}-\mathrm{NMR}$ $\left(100 \mathrm{MHz}, \mathrm{CDCl}_{3}\right) \quad \delta \quad 188.4,159.6,155.2, \quad 140.1,132.6$, $131.3,125.5,125.2,122.6,121.1,120.7,119.7,119.1,116.5$, 115.9, 113.4, 111.7, 108.9, 108.6, 50.6.

Pyrazoline 4의 합성. Chalcone $3(608 \mathrm{mg}, 2 \mathrm{mmol})$ 을 에탄올 $10 \mathrm{~mL}$ 에 가한 후 교반 하면서 hydrazine $(1 \mathrm{~mL})$ 을 적가하고, 약 $90^{\circ} \mathrm{C}$ 에서 3 시간 환류 시킨다. 반응 혼합물을 상온으로 냉 
<smiles>CCOc1ccccc1C=O</smiles>

1<smiles>COc1ccccc1C1CC(c2c(O)ccc3ccccc23)=NN1</smiles>

4

3<smiles>COc1ccccc1C1CC(c2c(O)ccc3ccccc23)=NN1C(=S)Nc1cc(OC)c(OC)c(OC)c1</smiles>

Fig. 1. Synthetic scheme for pyrazolinecarbothioamide (5).

각 시킨 후 형성된 고체를 여과하고 이를 에탄올에서 재결정하 여 $70 \%(446 \mathrm{mg})$ 의 수율로 pyrazoline 4 를 얻었다. Chalcone 3에 존재하던 탄소-탄소 간의 이중 결합은 pyrazoline 4 를 형성 함에 따라, 4번- 5 번 탄소 간의 단일결합으로 바뀌면서 $\mathrm{H}-5$ $(5.10 \mathrm{ppm}, \mathrm{dd}, J=3.0,10.2 \mathrm{~Hz})$ 와 두 개의 $\mathrm{H}-4(3.70 \mathrm{ppm}$, $\mathrm{dd}, J=10.2,16.7 \mathrm{~Hz}), \mathrm{H}-4$ ' $(3.00 \mathrm{ppm}, \mathrm{dd}, J=3.0,16.7 \mathrm{~Hz})$ 를 나타낸다. 4 번 탄소에 있는 두 개의 methylene 수소가 서로 다 른 화학적 환경에 있어 ${ }^{1} \mathrm{H}-\mathrm{NMR}$ 상 다른 화학적 이동을 나타내 고, germinal 짝지음 상수가 $16.7 \mathrm{~Hz}$ 로 매우 큰 것은 pyrazoline 화합물이 보이는 전형적인 양상이다(Acharya 등, 2010). 용융 점; $116-118^{\circ} \mathrm{C}$; ${ }^{1} \mathrm{H}-\mathrm{NMR}\left(400 \mathrm{MHz}, \mathrm{DMSO}^{\mathrm{d}} \mathrm{d}_{6}\right) \delta 12.33(\mathrm{~s}$, $1 \mathrm{H}), 8.24(\mathrm{~m}, 1 \mathrm{H}), 7.85(\mathrm{~m}, 1 \mathrm{H}), 7.73(\mathrm{~d}, J=3.0 \mathrm{~Hz}, 1 \mathrm{H})$, $7.54(\mathrm{td}, J=2.0,6.8,6.8 \mathrm{~Hz}, 1 \mathrm{H}), \quad 7.51 \quad(\mathrm{td}, \quad J=2.0,6.8$, $6.8 \mathrm{~Hz}, 1 \mathrm{H}), 7.43(\mathrm{~m}, 1 \mathrm{H}), 7.43(\mathrm{~d}, J=8.7 \mathrm{~Hz}, 1 \mathrm{H}), 7.41(\mathrm{~d}$, $J=8.7 \mathrm{~Hz}, 1 \mathrm{H}), 7.28(\mathrm{~m}, 1 \mathrm{H}), 7.04 \quad(\mathrm{dd}, J=0.8,8.2 \mathrm{~Hz}$, $1 \mathrm{H}), 6.95$ (td, $J=0.8,7.5,7.5 \mathrm{~Hz}, 1 \mathrm{H}), 5.10 \quad(\mathrm{dd}, \mathrm{H}-5$, $J=3.0,10.2 \mathrm{~Hz}, 1 \mathrm{H}), 3.85$ (s, $3 \mathrm{H}), 3.70$ (dd, $\mathrm{H}-4, J=10.2$, $16.7 \mathrm{~Hz}, 1 \mathrm{H}), 3.00(\mathrm{dd}, \mathrm{H}-4, J=3.0,16.7 \mathrm{~Hz}, 1 \mathrm{H}) ;{ }^{13} \mathrm{C}-\mathrm{NMR}$ $\left(100 \mathrm{MHz}, \mathrm{DMSO}-\mathrm{d}_{6}\right) \delta 156.6,153.2,153.1,133.7,129.8$, $128.4,127.5,127.0,126.3,125.4,124.7,123.9,122.3$, $120.3,118.5,110.8,110.1,56.4,55.5,39.5$.

Pyrazolinecarbothioamide 5의 합성. 피라졸린 $4(319 \mathrm{mg}, 1$ $\mathrm{mmol})$ 와 $3,4,5$-트리메톡시 이소티오시아네이트 $(225 \mathrm{mg}, 1 \mathrm{mmol})$ 를 에탄올 $10 \mathrm{~mL}$ 에 녹이고 약 $90^{\circ} \mathrm{C}$ 에서 8 시간 환류한다. 반 응 혼합물을 상온으로 낮추고 형성된 고체를 감압 여과하여 pyrazolinecarbothioamide $5(347 \mathrm{mg}, 64 \%)$ 를 얻었다. 각각의 수소는 correlated spectroscopy (COSY)를 통해 할당하였고, 탄 소는 heteronuclear multiple bonded connectivities (HMBC)를 통한 탄소-수소간의 상관관계를 통해 할당하여 Table 1에 나타 내었다. 용융점; $188-190^{\circ} \mathrm{C}$.

사이클린디-D1 (Cyclin D1) 단백질 발현 억제 효과. Pyrazolinecarbothioamide 5 대한 항암 효과를 확인하기 위하여, HCT116 대장암세포에 pyrazolinecarbothioamide $\mathbf{5}$ 를 처리한 후 암세포의
성장에 중요한 세포주기 조절 단백질인 사이클린 $\mathrm{D} 1$ 의 발현량 을 웨스턴 블롯법(Western blot assay)으로 분석하였고 그 결과 를 Fig. 2에 나타내었다(Koh, 2010). Pyrazolinecarbothioamide 5 를 처리하면 시간 의존적으로 사이클린 D1 단백질 발현양이 점차 감소되었다. 이때 대조 단백질인 glyceraldehyde 3-phosphate dehydrogenase (GAPDH)의 양은 변하지 않았으나 세포주기 진 행 억제 단백질인 p21 발현이 증가되었다. 이러한 결과는, pyrazolinecarbothioamide $\mathbf{5}$ 가 대장암세포에 작용하면 사이클린 D1 단백질 발현은 감소시키고, 세포주기 진행 억제 단백질인 $\mathrm{p} 21$ 단백질의 양은 증가시켜 암세포의 성장을 억제시킨다는 것 을 의미한다.

세포주기 진행 억제 효과. 세포주기 진행과정(cell cycle progression)의 분석은 세포 내 DNA 함량 측정을 통하여 하였 다. 세포 주기 중에서 $\mathrm{G} 1$ 주기 세포는 $2 \mathrm{~N}$ 함량의 $\mathrm{DNA}$ 를 포 함하며, $\mathrm{S}$ 기 세포는 $2 \mathrm{~N}$ 과 $4 \mathrm{~N}$ 사이의 양을, $\mathrm{G} 2$ 기와 $\mathrm{M}$ 주기 세포는 $4 \mathrm{~N}$ DNA 양을 포함한다. 사이클린 D1 단백질은 세포 주기의 $\mathrm{G} 1$ 단계에서 $\mathrm{S}$ 단계로 진행을 촉진하는 단백질이므로, pyrazolinecarbothioamide $\mathbf{5}$ 에 의해 사이클린 D1 단백질이 감소 되었을 때, 암세포의 세포 주기 진행이 손상되는 정도를 유세 포 분리 측정기(Flowcytometer; BD Science, USA)를 이용하여 조사하였다. HCT116 세포를 웨스턴 블롯 분석법과 동일하게 배양한 후, pyrazolinecarbothioamide 5 를 처리 하고 $0,24,48$ 시간 후에 트립신-EDTA(1\%)을 첨가해 세포를 배양기에서 때 어낸 후, $70 \%$ 에탄올로 세포를 고정시켰다. PI (Propidium Iodine)를 30 분간 반응하여 세포내 DNA를 염색한 후, DNA 양 의 변화를 측정하였다. 그 결과는 Fig. 3에 나타낸 바와 같다. 정상적으로 성장하고 있는 $\mathrm{HCT} 116$ 대장암세포에서 $\mathrm{G} 1$ 세포 주기를 가지는 세포는 약 $50.13 \%$ 였지만 pyrazolinecarbothioamide 5 를 처리한 세포군 에서는 처리 24 시간 후 $55.08 \%$ 로 증가하 였으며, 처리 48 시간 후에는 $60.18 \%$ 로 증가하였다. 또한, 대 조군 세포의 S기는 $19.73 \%$ 이었지만 pyrazolinecarbothioamide $\mathbf{5}$ 를 처리한 세포에서 $\mathrm{S}$ 주기 세포는 처리 24 시간과 48 시간 후 에 각각 14.28 와 $8.04 \%$ 로 시간에 따라 점차 감소하였다. 이때, 세 
Table $1{ }^{1} \mathrm{H}-\mathrm{NMR}$ and ${ }^{13} \mathrm{C}$-NMR assignment of pyrazolinecarbothioamide 5 through COSY and HMBC. CHn denotes the multiplicity of carbon obtained from the distortionless enhancement by polarization transfer (DEPT) experiment

\begin{tabular}{|c|c|c|c|c|c|}
\hline No. & $\delta$ of ${ }^{13} \mathrm{C}$ & $\mathrm{CHn}$ & $\delta$ of ${ }^{1} \mathrm{H}$ & COSY & HMBC \\
\hline 3 & 156.7 & $\mathrm{~s}$ & - & - & $\mathrm{C} 3-\mathrm{H} 4, \mathrm{H} 5$ \\
\hline 4 & 45.1 & $\mathrm{t}$ & $\begin{array}{l}2.97(\mathrm{dd}, 18.2,3.5) \\
4.12(\mathrm{dd}, 11.2,3.4)\end{array}$ & $\mathrm{H} 4-\mathrm{H} 5$ & - \\
\hline 5 & 58.8 & d & $6.25(\mathrm{dd}, 11.2,3.4)$ & $\mathrm{H} 5-\mathrm{H} 4$ & C5-H6" \\
\hline 6 & 173.2 & $\mathrm{~s}$ & - & - & - \\
\hline 7 & - & - & $9.86(\mathrm{~s})$ & - & - \\
\hline $1^{\prime}$ & 110.7 & s & - & - & C1'-H3', H8' \\
\hline $2^{\prime}$ & 154.7 & s & - & - & $\mathrm{C} 2{ }^{\prime}-\mathrm{H} 4{ }^{\prime}$ \\
\hline $3^{\prime}$ & 118.1 & $\mathrm{~d}$ & $7.21(\mathrm{~d}, 9.0)$ & H3'-H4' & - \\
\hline $4^{\prime}$ & 131.4 & $\mathrm{~d}$ & $7.87(\mathrm{~d}, 9.0)$ & H4'-H3' & C4'-H5' \\
\hline $5^{\prime}$ & 128.2 & d & $7.83(\mathrm{~d}, 8.0)$ & H5'-H6' & C5'-H4', H7' \\
\hline $6^{\prime}$ & 123.0 & $\mathrm{~d}$ & $7.33(\mathrm{ddd}, 8.0,6.9,1.4)$ & $\begin{array}{l}\text { H6'-H5' } \\
\text { H6'-H7' }\end{array}$ & C6'-H8' \\
\hline $7^{\prime}$ & 127.2 & d & 7.48 (ddd, $8.5,6.9,1.0)$ & $\begin{array}{l}\mathrm{H} 7{ }^{\prime}-\mathrm{H} 6 \\
\mathrm{H} 7{ }^{\prime}-\mathrm{H} 8^{\prime}\end{array}$ & C7'-H5' \\
\hline $8^{\prime}$ & 123.8 & $\mathrm{~d}$ & $8.09(\mathrm{~d}, 8.5)$ & $\mathrm{H} 8^{\prime}-\mathrm{H} 7^{\prime}$ & C8'-H6' \\
\hline $9^{\prime}$ & 132.2 & $\mathrm{~s}$ & - & - & C9'-H4', H5', H7' \\
\hline $10^{\prime}$ & 127.7 & $\mathrm{~s}$ & - & - & C10'-H3', H6', H8' \\
\hline $1 "$ & 129.6 & $\mathrm{~s}$ & - & - & C1"-H4, H3", H5" \\
\hline $2^{\prime \prime}$ & 155.7 & s & - & - & C2"-H4", H6", H2"OMe \\
\hline $3 "$ & 111.3 & $\mathrm{~d}$ & $7.06(\mathrm{~d}, 8.0)$ & H3"-H4" & C3"-H5" \\
\hline $4 "$ & 128.3 & d & $7.27(\mathrm{~m})$ & $\begin{array}{l}\text { H4"-H3" } \\
\text { H4"-H5" }\end{array}$ & C4"-H6" \\
\hline $5^{\prime \prime}$ & 120.2 & $d$ & $6.98(t, 7.5)$ & $\begin{array}{l}\mathrm{H} 5 "-\mathrm{H} 4 " \\
\mathrm{H} 5 "-\mathrm{H} 6 "\end{array}$ & C5"-H3" \\
\hline $6 "$ & 125.6 & d & $7.17(\mathrm{dd}, 7.5,1.4)$ & H6"-H5" & C6"-H4" \\
\hline $1^{\prime \prime \prime}$ & 135.3 & $\mathrm{~s}$ & - & - & - \\
\hline 2"'6"' & 102.2 & $d$ & $7.09(\mathrm{~s})$ & - & C2"'-NH7 \\
\hline 3"'5"' & 152.0 & $\mathrm{~d}$ & - & - & - \\
\hline 4"' & 134.3 & $\mathrm{~s}$ & - & - & C4"'-H2"', H4"'OMe \\
\hline 2"-OMe & 55.5 & $q$ & $3.85(\mathrm{~s})$ & - & - \\
\hline 3"',5"'-OMe & 55.8 & $\mathrm{q}$ & $3.72(\mathrm{~s})$ & - & - \\
\hline 4"'-OMe & 60.0 & q & $3.64(\mathrm{~s})$ & - & - \\
\hline 2'-OH & - & - & $10.42(\mathrm{bs})$ & - & - \\
\hline
\end{tabular}

q: quartet; t: triplet; d: doublet; s: singlet

\section{Compound 5.}

oh $6 \mathrm{~h} 12 \mathrm{~h} 24 \mathrm{~h}$

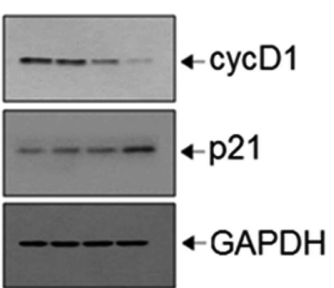

Fig. 2. Effect of pyrazolinecarbothioamide (5) on the expression of cell cycle regulatory proteins. After treatment with $20 \mu \mathrm{M}$ of pyrazolinecarbothioamide (5) for $48 \mathrm{~h}$, level of p21 increased, where the cyclin D1 decreased and GAPDH unchanged.

포사멸을 의미하는 sub-G1 세포의 양은 pyrazolinecarbothioamide $\mathbf{5}$ 를 처리시간에 따라 0.99 에서 $3.12 \%$ 로 점차 증가 되는 것이 관찰되었다. 이러한 결과를 통해 pyrazolinecarbothioamide 5는
$\mathrm{HCT} 116$ 대장암 세포의 $\mathrm{G} 1$ 단계에서 $\mathrm{S}$ 단계로의 진행을 차단하 여 암세포의 성장을 억제시킬 수 있다는 사실을 확인할 수 있다. 대장암 세포주 성장 억제 효과. Pyrazolinecarbothioamide 5에 처리에 의해 HCT116 대장암 세포의 세포주기 진행이 억제되 었으므로, 이로 인한 HCT116 대장암 세포의 성장능이 억제되 는지를 CCK-8 키트(CellCounting Kit-8; Dojindo, Japan)를 이 용하여 측정하였다. HCT116 대장암세포를 96-well 세포 배양 판에 $1 \times 10^{4}$ 개 되도록 분주한 후 $0,5,10,20 \mu \mathrm{M}$ 농도의 pyrazolinecarbothioamide 5 화합물을 처리하고, 각각 24 시간과 48 시간 후에 CCK-8 용액 $10 \mu \mathrm{L}$ 를 첨가하였다. 2 시간 후에 세포배양액의 흡광도를 $450 \mathrm{~nm}$ 에서 측정하여 세포 생존능을 분 석하였다. 그 결과는 Fig. 4에 나타낸 바와 같이 아무 처리하지 않은 대조 세포군 에서는 세포 성장능이 시간에 따라 증가하였 지만, pyrazolinecarbothioamide 5 를 처리한 세포군 에서는 처리 농도와 시간 의존적으로 세포 성장이 감소되었다. 이러한 결과 는 pyrazolinecarbothioamide $\mathbf{5}$ 화합물에 의해 대장암세포의 세 포 주기 진행이 억제되어 궁극적으로 암세포 성장이 저해되었 


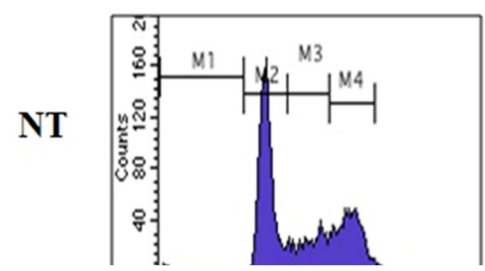

sub-G1 $0.99 \%$

G1 $50.13 \%$

S $19.73 \%$

G2/M $28.96 \%$

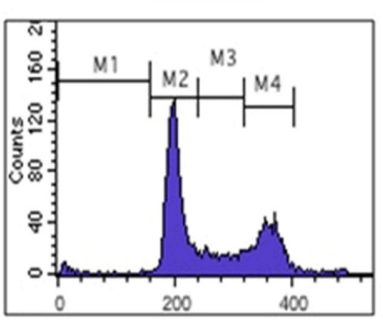

sub-Gl $\quad \mathbf{1 . 3 2} \%$

\begin{tabular}{l} 
G $\quad \mathbf{5 5 . 0 8} \%$ \\
\hline
\end{tabular}

G2/M $28.48 \%$

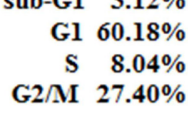

$48 h$

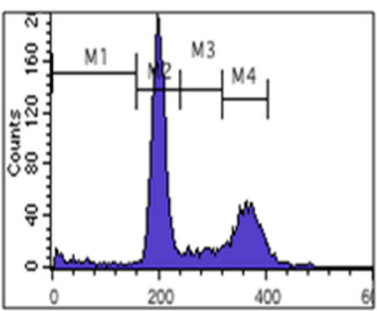

Fig. 3. Pyrazolinecarbothioamide (5) treatment arrested the cell cycle progression at the G1 phase for HCT116 cancer cell.

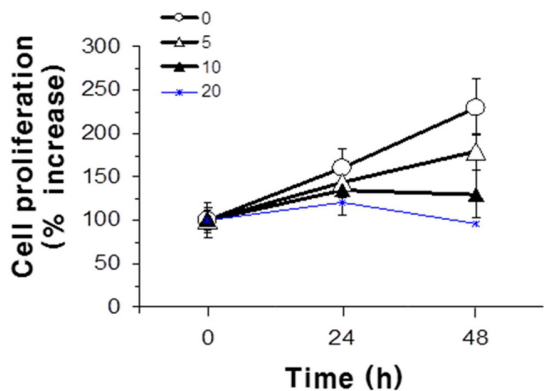

Fig. 4. Effect of pyrazolinecarbothioamide (5) on the cell survival of HCT116 cells. HCT116 cells were treated with different doses $(0,5,10$, or $20 \mu \mathrm{M}$ ) of pyrazolinecarbothioamide (5) for varying lengths of time (24-48 h). Cell proliferation rate was determined by Cell Counting Kit-8.

\section{음을 의미한다.}

본 연구에서는 새로운 pyrazolinecarbothioamide 5 를 합성하 였고 이 화합물을 HCT116 대장암 세포에 처리하였을 때, 세포 주기 조절 단백질인 사이클린 D1의 발현이 억제되는 것을 확 인하였다. 이 같은 결과로 이 화합물은, 세포 주기를 G1 단계 에서 $\mathrm{S}$ 단계로 진행되는 것을 저해하였고, 이로 인한 암세포의 성장을 억제하는 항암효능을 나타내었다. 본 연구는 기존의 항 암 연구(Havrylyuk 등, 2009; Congui 등, 2010)에 주로 사용되 는 NCI (National Cancer Institute) 인간 암세포주에 대한 무작 위 screening과는 달리, 항암의 원인을 우선 규명을 하고 항암 효과를 측정하는 방법을 사용하였고, 이는 추후 구조-활성연구 등 체계적인 연구를 하는데 기초를 제공한다. 또한 구조적인 면 에서, 최근 항암 효과를 나타내는 것으로 보고된(Bano 등, 2011) pyrazoline 계열의 화합물은 2번 질소에 벤젠 설폰아마이
드를 포함하는 특이성을 보이나 기존에 보고된 다른 pyrazoline 화합물들처럼 3 번, 5 번 위치가 모두 벤젠 고리로 치환된 공통 점을 가지고 있다. 하지만 이번에 보고하는 pyrazolinecarbothioamide 5 는 2 번 위치에 thioamide기를 가질 뿐만 아니 라, 특히 5 번 위치에 일반적인 벤젠고리 대신 나프틸 고리를 가 지는 구조적인 특성을 지니고 있는 신규화합물이다. 현재 이 계 열의 다양한 유도체가 합성되고 있고 이를 통한 구조-활성관계 를 규명하여 새로운 형태의 항암제 선도물질을 개발하려 한다.

감사의 글 이 논문은 2011-12년도 동덕여자대학교 학술연구비 지원에 의하 여 수행된 것임.

\section{References}

Acharya BN, Saraswat D, Tiwari M, Shrivastava AK, Ghorpade R, Bapna S et al. (2010) Synthesis and antimalarial evaluation of 1, 3, 5-trisubstituted pyrazolines. Eur J Med Chem 45, 430-8.

Ahsan MJ, Samya JG, Khalilullaha H, Bakhtc MA, and Hassan MZ (2011) Synthesis and antimycobacterial evaluation of 3a,4-dihydro- $3 H$-indeno [1,2-c] pyrazole-2-carboxamide analogues. Eur J Med Chem 46, 5694-7.

Bano S, Javed K, Ahmad S, Rathish IG, Singh S, and Alam MS (2011) Synthesis and biological evaluation of some new 2-pyrazolines bearing benzene sulfonamide moiety as potential anti-inflammatory and anticancer agents. Eur J Med Chem 46, 5763-8.

Bazzaro M, Anchoori RK, Mudiam KMR, Issaenko O, Kumar S, Karanam B et al. (2011) Alpha-beta-Unsaturated carbonyl system of chalcone-based derivatives is responsible for broad inhibition of proteasomal activity and preferential killing of human papilloma virus (HPV) positive cervical cancer cells. J Med Chem 54, 449-56.

Congiu C, Onnis V, Vesci L, Castronia M, and Pisano C (2010) Synthesis and in vitro antitumor activity of new 4,5-dihydroxypyrazol derivatives. Bioorg Med Chem 18, 6238-48.

Cordon-Cardo C (1995) Mutations of cell cycle regulators. Biological and clinical implications for human neoplasia. Am J Pathol 147, 545-60.

Gao J, Liu Y-G, Zhou Y, Boxer LM, Woolley FR, and Zingaro RA (2007) Artificial zinc(II) complexes regulate cell cycle and apoptosis-related gene in tumor cell lines. ChemBioChem 7, 332-40.

Havrylyuk D, Zimenkovsky B, Vasylenko O, Zaprutko L, Gzella A, and Lesyk R (2009) synthesis of novel thiazolone-based compounds containing pyrazolone moiety and evalution of their anti-cancer activity. Eur J Med Chem 44, 1396-404.

Hsieh C-T, Hsieh T-J, El-Shazly M, Chuang D-W, Tsai Y-H, Yen C-T et al. (2012) Synthesis of chalcone derivatives as potential anti-diabetic agents. Bioorg Med Chem Lett 22, 3912-5.

Joshi RS, Mandhane PG, Diwakar SD, Dabhade SK, and Gill GH (2010) Synthesis, analgesic and anti-inflammatory activities of some novel pyrazoline derivatives. Bioorg Med Chem Lett 20, 3721-5.

Koh D (2010) Synthesis of salens and their cobalt complexes from meso-1,2diamine and their anti-cancer property. J Appl Biol Chem 53 108-11.

Maccioni E, Alcaro S, Orallo F, Cardia MC, Distinto S, Costa G et al. (2010) Synthesis of new 3-aryl-4,5-dihydropyrazole-1-carbothioamide derivatives. An investigation on their ability to inhibit monoamine oxidase. Eur $J$ Med Chem 45, 4490-8.

Rao YK, Kao T-Y, Ko J-L, and Tzeng Y-M (2010) Chalcone HTMC causes in vitro selective cytotoxicity, cell-cycle G1 phase arrest through p53dependent pathway in human lung adenocarcinoma A549 cells, and in vivo tumor growth suppression. Bioorg Med Chem Lett 20, 6508-12.

Siddiqui ZN, Musthafa TNM, Ahmad A, and Khan AU (2011) Thermal solvent-free synthesis of novel pyrazolylchalcones and pyrazolines as potential antimicrobial agents. Bioorg Med Chem Lett 21, 2860-5.

Wu J, Li J, Cai Y, Pan Y, Ye F, Zhang Y et al. (2011) Evaluation and discovery of novel synthetic chalcone derivatives as anti-inflammatory agents. J Med Chem 54, 8110-23. 